\title{
Verification of Fungicide and Its Application Frequency for Management of Frog Eye Leaf Spot (Cercospora capcisi) on Hot Pepper Under Rain Fed Condition at Bako
}

\author{
Feyera Takele Degefa \\ Bako Agricultural Research Center, P. O. Box 03, Bako, West Shewa, Ethiopia
}

\begin{abstract}
Cercospora leaf spot is caused by Cercospora capcisi is an important disease which reduces the productivity of hot pepper (Capsicum spp.). Field experiment was conducted to evaluate different fungicides and its application frequencies against Cercospora leaf spot in order to select an important fungicides and its application frequency at Bako Agricultural Research Center. The experiment was laid out in randomized complete block design with three replication. Two different fungicides (Mancozeb 80WP and Trust-Cymocop 439.5WP) and four application frequencies (two, three, four and five) times with untreated control were used. Data on disease severity, area under disease progress curve, marketable yield and unmarketable yield of hot pepper were recorded. The result revealed that, both fungicides sprayed control Cercospora leaf spot which is significantly different from untreated check in disease severity, area under disease progress curve (AUDPC) and marketable yield. However, application frequencies of fungicides were not significantly different on disease severity, AUDPC and marketable yield of the plant. Application of Trust Cymocop 439.5WP reduces 26.67\% relative yield loss of hot pepper over control check. An economic analysis was done for fungicides and shows feasibility of fungicide application for management of Cercospora leaf spot. Fungicide which has the highest Marginal Rate of Return was used for recommendation. Two times application of Trust-Cymocop 439.5WP was recommended to reduce disease severity and yield loss of the plant.
\end{abstract}

Keywords: Cercospora leaf spot, frequency, hot pepper, and trust-Cymocop 439.5WP

DOI: $10.7176 / \mathrm{JNSR} / 12-9-01$

Publication date:May $31^{\text {st }} 2021$

\section{Background and Justification}

Hot pepper (Capsicums spp.) is the most common type of Capsicum spp which belongs to the family of Solanaceae. It is one of major vegetable and spice crops loved for its aroma, taste, flavor and pungency (Zewdie et al., 2004). The crop is produced for cooking and vegetable. According to FAO (2002) report, world production of pepper was 21,719,000 metric tons on 1.59 million hectare of land, of which Africa contributed 2,027,000 (9.3\%) metric tons on 0.264 million hectare of land. Fekadu and Dandena, (2006) reported the productivity and production of hot pepper is low due to low yielding varieties, drought, pests and poor cultural practices.

From pest's factor, diseases caused by different fungi, bacteria and viruses are the major constraints of hot pepper production. Frogeye leaf spot is a disease of pepper caused by fungus Cercospora capsici and most damaging in tropical and subtropical environments. Infection occurs when spores land on and directly penetrate leaves through natural openings and also disseminated by wind, splashing water, or by contaminated equipment. For this reason, the yield of hot pepper much limited in the area. To alleviate this problem introducing effective fungicide and its application frequency is relevant to conduct the experiment.

\section{Materials and Method}

Field experiment was conducted at Bako during rainy season of 2015 and16. Marekofana variety which currently under production will be planted on plot size $3.5 \mathrm{~m}$ x $3 \mathrm{~m}$. Experiment was designed in randomized complete block design with three replication. The spacing between row and plants was $70 \mathrm{~cm}$ and $30 \mathrm{~cm}$ respectively. Two foliar fungicide (Maneb and Kocide) was used for the experiment. Two foliar fungicide application was started after disease onset ( $>5 \%$ incidence) to the physiological maturity was applied to full leaf coverage at 7 to 10 day intervals

\footnotetext{
Data collected:

* Disease parameters (Disease severity per plant and Disease incidence)

* Weight of marketable yield per plot at dry weight

* Weight of unmarketable yield per plot at dry weight
}

Data analysis

Disease severity per sampled plant was converted to severity index per plots for each assessment period. Area 
under disease progress curve (AUDPC \%-day) was calculated plot base and standardized by dividing to epidemic period. Standardized AUDPC, severity index and yield data was subjected to ANOVA for significance test using SAS 9.2 version applying PROC GLM Model. Analysis was done after appropriate data transformation for fattiness of ANOVA. Significantly varied means were separated at $\mathrm{p}<0.05$ using Least Significant Difference.

\section{Result and Discussion}

\section{Effects of fungicide application on disease Severity}

Cercospora leaf spot of hot pepper was first observed at 88 days after transplanting. However, the diseases assessment was started at 95 days after transplanting. The application frequency of fungicide were not significantly $(\mathrm{P} \leq 0.05)$ different in terms of their respective reaction to the diseases i.e. all two times, three times, four times and five times were not significantly different on disease severity. As well as the interaction between Fungicide and application frequencies were not significantly $(\mathrm{P} \leq 0.05)$ affect all collected parameters.

The applied fungicides were significantly affect severity of Cercospora leaf spot of hot pepper when compared with unsprayed check (Figure: 1$)$. The plots showed significantly $(\mathrm{P} \leq 0.05)$ different levels severity of Cercospora leaf spot of Hot pepper starting from the first date of disease assessment (95DAT). However, none of these fungicides fully prevented the development of the disease. The maximum mean severity recorded was $45.77 \%$ on the unsprayed plots, while the lowest mean severity $(15.87 \%)$ was recorded on the plot sprayed with Trust Cymocop 439.5WP followed by plot sprayed with Mancozeb 80WP (20.70\%) (Figure: 1).

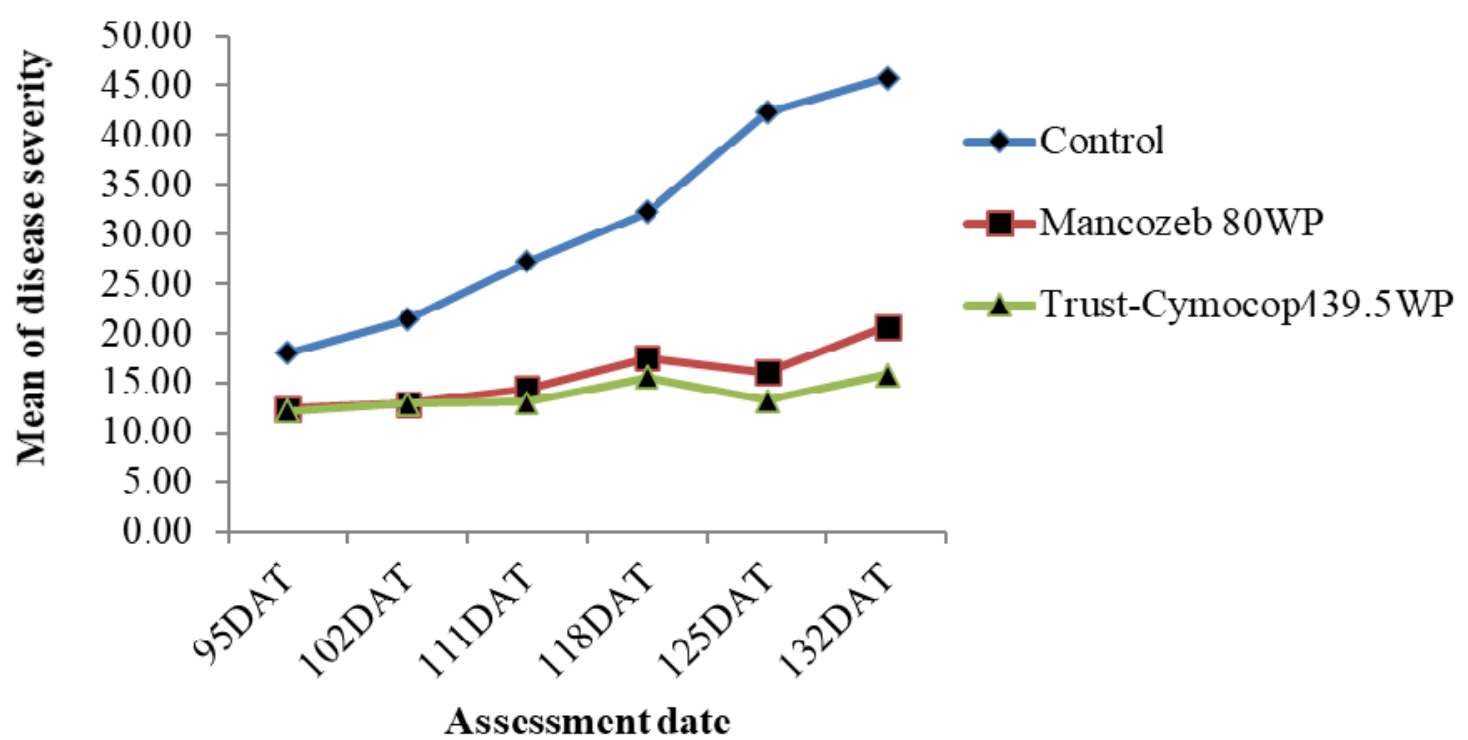

Fig: 1.The disease severity mean of Cercospora leaf spot of hot pepper progress at 2015 and 2016 main cropping season.

Effects of Fungicide application on Area under Disease Progress Curve (AUDPC)

The area under disease progress curve (AUDPC) is used to combine multiple observations of disease progress into a single value. Spraying fungicides (Trust Cymocop 439.5WP and Mancozeb 80WP) significantly $(\mathrm{P} \leq 0.05)$ reduced the AUDPC values compared to unsprayed control (Figure: 2). However, the difference between Trust Cymocop 439.5WP and Mancozeb 80WP in AUDPC values was not statistically significant (Figure: 2). Application frequencies and there interaction with fungicide were not significant on area under disease progress curve (AUDPC). The result of the study revealed that the maximum AUDPC (1111.51\%day) obtained from unsprayed control while the lowest AUDPC (495.67\%day and 557.18\%day) was recorded from Trust cymocop 439.5WP and Mancozeb 80WP respectively. 


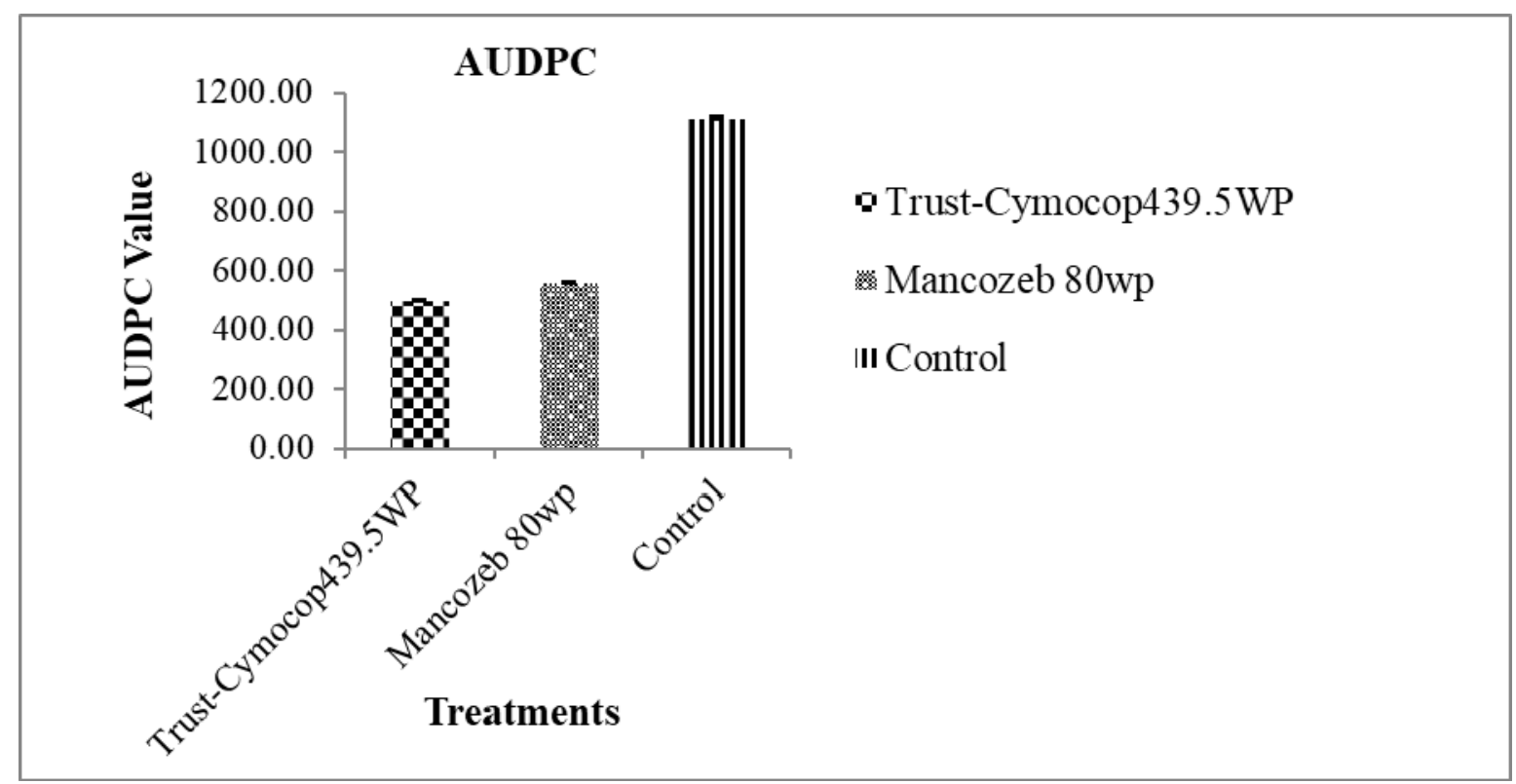

Fig: 2. Effects of Fungicide application on AUDPC at 2015 and 2016 main cropping season

\section{Effects of fungicide application on marketable yields of hot pepper production}

Cercospora leaf spot of hot pepper affects the quality and yield of the plant. The result of the study was revealed that there was significantly $(\mathrm{P} \leq 0.05)$ different marketable yield between treatments due to fungicide application. However, application frequencies and there interaction with fungicide was not significantly $(\mathrm{P} \leq 0.05)$ affected marketable yield of the plant. The maximum marketable yield was obtained from plot treated by Trust cymocop 439.5WP (20.97 quintals/ha) which was followed by plot treated with Mancozeb80WP (18.63quantals/ha) while the lowest marketable yield (15.31quantals/ha) was recorded from untreated check (Figure: 3 ).

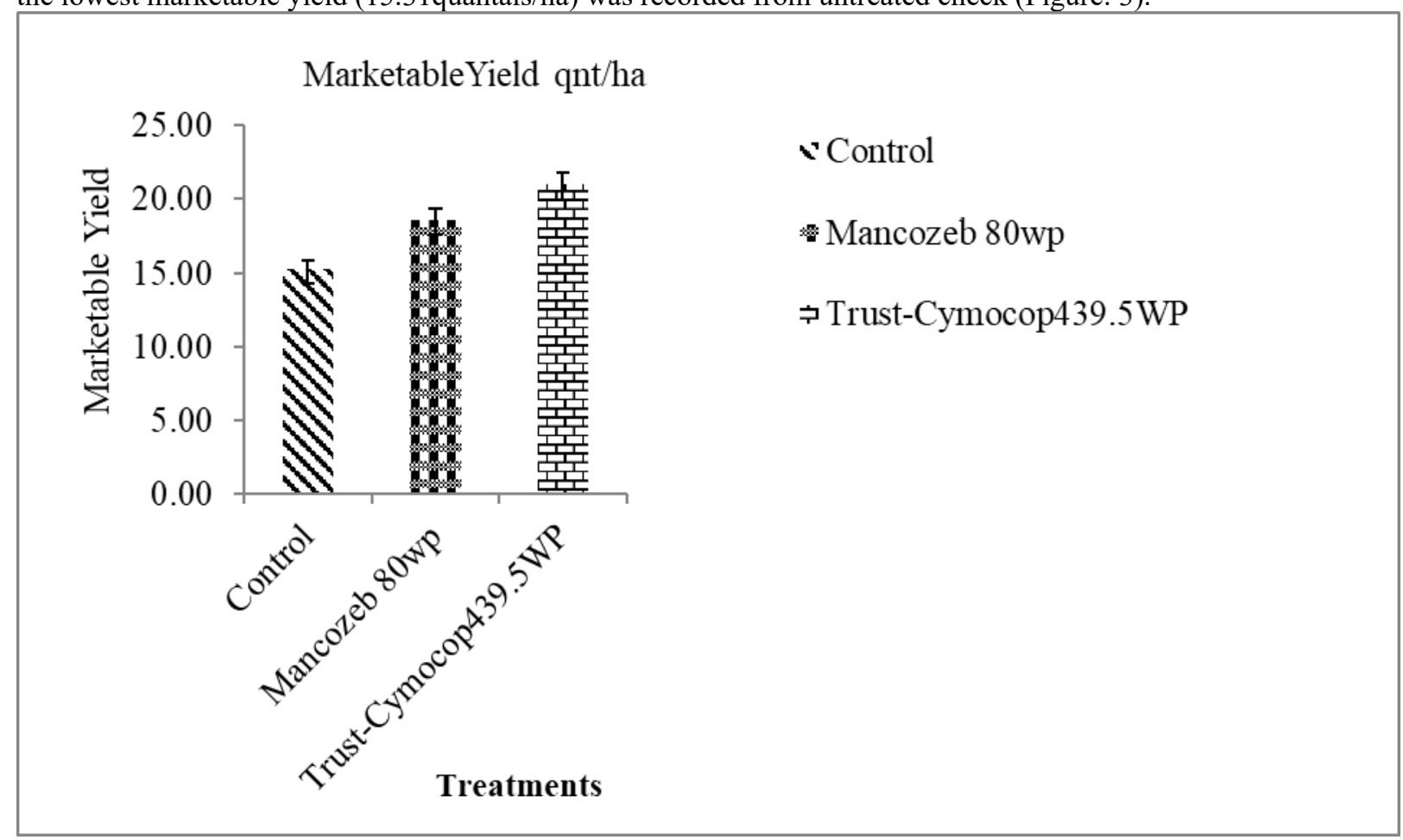

Figure: 3: Yield performance of hot pepper under fungicide management of Cercospora leaf spot disease

\section{Relative yield loss}

Cercospora leaf spot (Cercospora capcisi) is an important disease which reduces quantity and quality of hot pepper yield. The current study was revealed that production of hot pepper is $26.98 \%$ relative yield loss due to Cercospora leaf spot without fungicide application during its production period. Applying Trust Cymocop 439.5 
WP was reduce relative yield loss by $26.98 \%$ when it compared with unsprayed plot and $11.14 \%$ relative yield loss when it compared with plot treated by Mancozeb 80WP fungicide.

\section{Regression and Correlation of Cercospora leaf spot}

The result of the study revealed that the correlation between Cercospora leaf spot and the hot pepper yield was significant and they were indirectly correlated. However, there correlation strength was intermediate correlations (Table: 1)

\begin{tabular}{ll}
\hline Disease parameters & Yield(qt) \\
\hline 95DAT & $-0.322^{*}$ \\
102DAT & $-0.262 \mathrm{~ns}$ \\
11 DAT & $-0.392^{* *}$ \\
$118 \mathrm{DAT}$ & $-0.332^{*}$ \\
125DAT & $-0.424 * *$ \\
132DAT & $-0.415^{* *}$ \\
AUDPC & $-0.403 * *$ \\
\hline
\end{tabular}

Table: 1 Correlation of Cercospora leaf spot with hot pepper yield

Based on the result obtained as severity of Cercospora leaf spot increased by $1 \%$ the yield of hot pepper decreased by $0.15 q t$ (Fig:2).

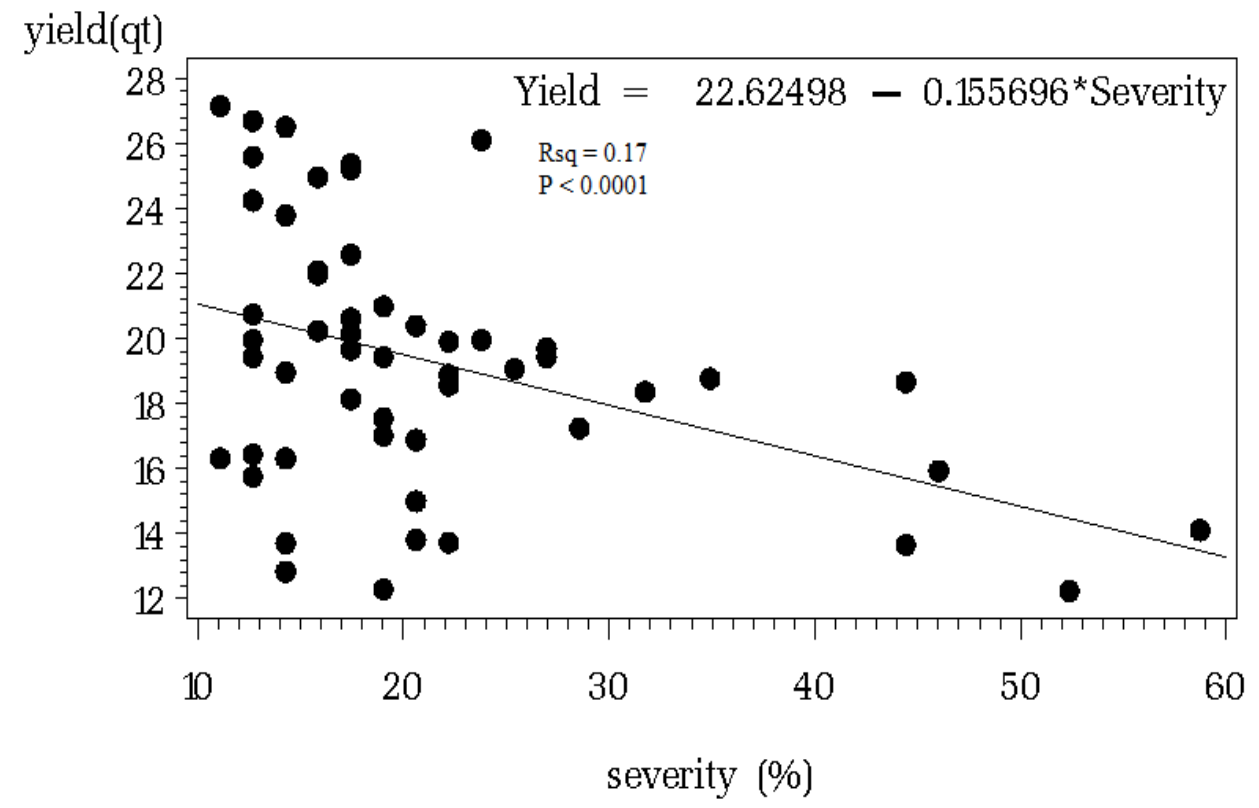

Fig: 4 Regression of Cercospora leaf spot disease with hot pepper yield

\section{Partial budget analyses}

The result of the study revealed that application frequencies of both fungicides were not significantly affecting the yield of hot pepper. However, fungicides application were signicantly affect the yield of hot pepper. So, the minimum application frequency was used for partial budget analyses to recommendation of the result

Table 1: shows the fungicide costs, fungicide application costs and hot pepper prices used for economic analyses.

\begin{tabular}{|l|c|l|l|l|l|r|l|r|}
\hline & $\begin{array}{l}\text { Freq- } \\
\text { uency }\end{array}$ & $\begin{array}{l}\text { Adjusted } \\
\text { Yield } \\
\text { qunts/ha }\end{array}$ & $\begin{array}{l}\text { Gross } \\
\text { Return } \\
\text { birr/ha }\end{array}$ & $\begin{array}{l}\text { Fungicide } \\
\text { Costs }\end{array}$ & $\begin{array}{l}\text { fungicide } \\
\text { application } \\
\text { costs }\end{array}$ & $\begin{array}{l}\text { Variable } \\
\text { Cost } \\
\text { birr/ha }\end{array}$ & $\begin{array}{l}\text { Net } \\
\text { Benefit } \\
\text { birr/ha }\end{array}$ & $\begin{array}{l}\text { MRR } \\
(\%)\end{array}$ \\
\hline Mancozeb 80WP & 2 & 15.23 & 60914.29 & 1360 & 400 & 1760 & 59154.29 & 229.00 \\
\hline $\begin{array}{l}\text { Trust- } \\
\text { Cymocop439.5WP }\end{array}$ & 2 & 17.52 & 70095.24 & 1260 & 400 & 1660 & 68435.24 & 801.89 \\
\hline Control & 0 & 13.78 & 55123.81 & 0 & 0 & 0 & 55123.81 & 0.00 \\
\hline
\end{tabular}




\section{Conclusion and Recommendation}

Application of fungicides for management of Cercospora leaf spot of hot pepper is an important option to increase yield and quality of hot pepper production. From the result of the study both fungicides were significantly reduces disease severity and AUDPC and increases marketable yield when compared with untreated control. Application of Trust-Cymocop439.5wp fungicide was the best control method of Cercospora leaf spot rather than Mancozeb $80 \mathrm{wp}$; because the highest yield was recorded from plot treated by Trust-cymocop439.5wp but not significantly difference from plot treated by mancozeb80wp. However, application frequency was not significantly affected disease severity, AUDPC and marketable yield of hot pepper. For these reason the minimum application frequency was used for partial budget analyses with the control check. Based on partial budget analyses two times application of Trust-Cymocop439.5wp after 5\% disease incidence was appeared is economically feasible and recommended as Cercospora leaf spot management options.

\section{REFERENCES}

FAO, 2002. Food and Agricultural Organization, Production Yearbook. FAO Statistics Series No 176, Vol. 56.

Fekadu, M. and Dandena, G. 2006. Status of Vegetable Crops in Ethiopia.

Ray Cercauskas, 2004.Production of Pepper and other vegetables. AVRDC publication 04-575.

Rubatzky, V.E and M. Yamaguchi M., 1997. World vegetables: principles, production and nutritive values, $2^{\text {nd }}$ edition, Chapman and Hall International Thomson Publishing, New York, 843p. 